
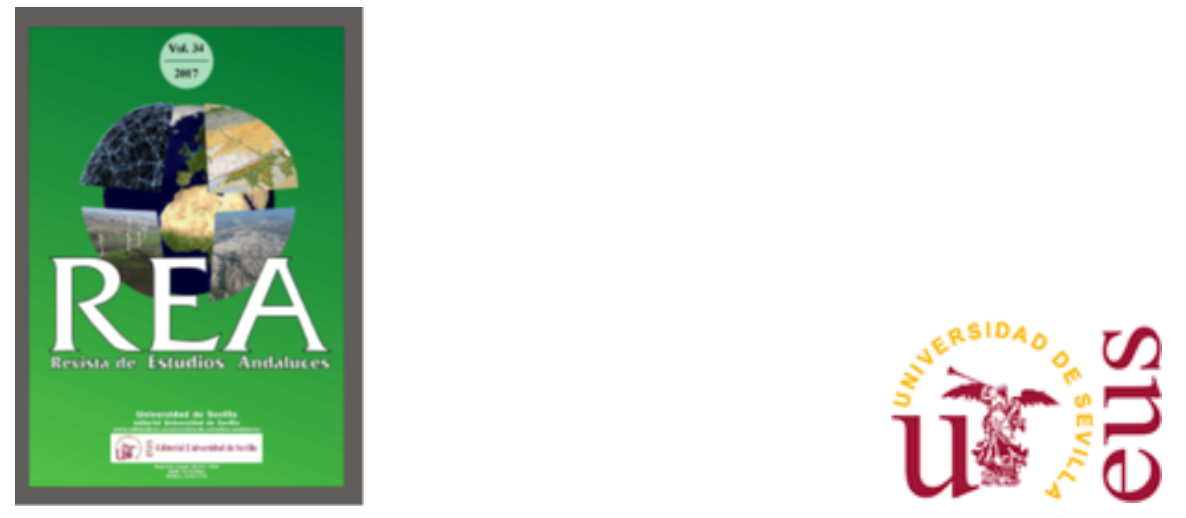

Revista de Estudios Andaluces (REA)

e-ISSN: $2340-2776$.

REA Vol. 34 (2017). http://dx.doi.org/10.12795/rea.2017.i34

\title{
El Conocimiento Científico de la Alta Velocidad Española y su Relación con el Turismo a través del Análisis Bibliográfico
}

\section{The Scientific Kowledge of Spanish High-Speed Rail and its Relationship with Tourism through Bibliographic Analysis}

\author{
Aida Pinos-Navarrete \\ Universidad de Granada \\ aida93@correo.ugr.es \\ Carmen Mínguez-García \\ Universidad Complutense de Madrid \\ cminguez@ghis.ucm.es
}

Formato de cita / Citation: Pinos-Navarrete, Aida y Mínguez-García, Carmen (2017). El Conocimiento Científico de la Alta Velocidad Española y su Relación con el Turismo a través del Análisis Bibliográfico. Revista de Estudios Andaluces, vol. 34 (1), 321-349. http://dx.doi.org/10.12795/rea.2017.i34.11

Enlace artículo / to link to this article: http://dx.doi.org/10.12795/rea.2017.i34.11

\section{(c) (1) $(9)$}

SinObraDerivada 4.0 Internacional

http://editorial.us.es/es/revista-de-estudios-andaluces

https://ojs.publius.us.es/ojs/index.php/REA 


\title{
El Conocimiento Científico de la Alta Velocidad Española y su Relación con el Turismo a través del Análisis Bibliográfico
}

\section{The Scientific Kowledge of Spanish High-Speed Rail and its Relationship with Tourism through Bibliographic Analysis}

\author{
Aida Pinos-Navarrete \\ Universidad de Granada \\ aida93@correo.ugr.es \\ Carmen Mínguez-García \\ Universidad Complutense de Madrid \\ cminguez@ghis.ucm.es
}

Recibido: 6 de marzo, 2017

Revisado: 21 de mayo, 2017

Aceptado: 25 de mayo, 2017

\section{Resumen}

Se analiza la producción científica dedicada al estudio de los principales aspectos territoriales y socioeconómicos de la red de la alta velocidad española, con el objetivo de comprender su evolución y las temáticas abordadas. Los resultados, estructurados por disciplinas, avalan la hipótesis de que en España la relación entre el AVE y el turismo ha sido todavía poco estudiada, pese a su interés científico y político. Por ello, se presenta como una importante línea de investigación que ha de abordar la definición de una serie de preguntas, que deben ser resueltas en colaboración entre expertos de diferentes áreas que aporten distintas perspectivas y metodologías.

Palabras clave: Red de alta velocidad, turismo, producción bibliográfica, retos de investigación, multidisciplinariedad.

\section{Abstract}

The scientific production, which focused on the study of the main territorial and socioeconomic issues of the Spanish High-speed rail network, is analyzed in depth. This research aims to understand its evolution and designated topics. The results, classified by disciplines, support the hypothesis that in Spain the relationship between High-speed rail and tourism has yet to be thoroughly studied, despite its scientific and political interest. For this reason, future research must tackle a variety of questions which must 
be addressed through a collaboration of experts from different areas that contribute to different perspectives and methodologies.

Keywords: High-Speed rail Network, tourism, scientific literature, research challenges, multidisciplinary.

Revista de Estudios Andaluces, vol. 34, núm. 1 (2017) pp. 321-349. e-ISSN: 2340-2776

http://dx.doi.org/10.12795/rea.2017.i34.11

(c) (i) @( $)$ Esta obra se distribuye con la licencia Creative Commons Reconocimiento-NoComercialSinObraDerivada 4.0 Internacional 


\section{INTRODUCCIÓN}

La alta velocidad tiene su origen en Japón donde en el año 1964 se inauguró la primera línea que cubría el trayecto Tokio-Osaka. En Europa no fue hasta 1981 cuando se puso en funcionamiento con la vía que unía París con Lyon. Desde entonces se expandió progresivamente a otros países del continente como Alemania, Italia, Bélgica, Países Bajos, Reino Unido o España, generando gran interés social y convirtiéndose en objeto de estudio. Concretamente, los científicos franceses abrieron un campo de conocimiento y una importante línea de publicaciones todavía activa (Bonnafous, 1987; Troin, 1995, 1997; Auphan, 2002; Soulié y Tricoire, 2002; Delaplace, 2012; Bazin et al, 2014; entre otros). A medida que la alta velocidad se fue implantando en otros países, sus investigadores la incorporan como parte esencial de sus estudios y publicaciones, en las que abordan el fenómeno a nivel europeo (Spiekermann y Wegener, 1994 y 1996; Cinotti y Treboul, 2000; Charlon y Gibb, 2000) y mediante estudios de casos.

España dispone de una de las redes de alta velocidad más extensas a nivel mundial que, desde abril de 1992, se ha expandido a más de una veintena de ciudades, en su mayoría capitales de provincia (Gutiérrez, 2013). Esta red ha generado un gran interés mediático, pero también en el ámbito político, económico, social y académico-científico (Bellet et al., 2010). Dentro este último campo especialistas de diferentes ciencias llevan décadas estudiando sus procesos y consecuencias, que se reflejan en una producción copiosa, multidisciplinar y de gran calidad, que presenta numerosos matices. Precisamente, esta actividad ha despertado gran interés en la geografía y en economía, generando líneas y grupos de trabajo especializados en analizar sus causas e impactos. En este sentido, y pese a que el desplazamiento es intrínseco al turismo, todavía son poco frecuentes los trabajos que lo relacionan con la alta velocidad como modo de transporte utilizado para el desplazamiento, mientras que son habituales los estudios que lo han vinculado con los desplazamientos aéreos, especialmente con las líneas de bajo coste (Vera e Ivars, 2009; Pulido, 2007; Saladié, 2014; Díez, 2012b; entre otros).

\section{METODOLOGÍA}

El objetivo de este artículo es doble y consiste, en primer lugar, en analizar la evolución y temáticas abordadas en el conocimiento de la alta velocidad en España, a través de las publicaciones científicas centradas en el estudio de los principales aspectos territoriales y socioeconómicos. Y, en segundo lugar, pretende conocer la relación AVE-turismo y cómo se ha abordado desde la investigación; ya que se parte de la hipótesis de que pese a que en España el AVE ha generado una línea de investigación potente y consolidada, su relación con el turismo ha sido poco estudiada.

Revista de Estudios Andaluces, vol. 34, núm. 1 (2017) pp.321-349. e-ISSN: 2340-2776 http://dx.doi.org/10.12795/rea.2017.i34.11

\section{c) (i) (3)}

SinObraDerivada 4.0 Internacional 
Se ha realizado una detallada revisión bibliográfica de la producción científica. Para seleccionar los textos relativos a los estudios de caso españoles no se han seguido criterios muy restrictivos, puesto que se buscaba dar un enfoque multidisciplinar, tal y como se muestra en la presentación de los resultados según la orientación académica de sus autores principales: economía, ingeniería, geografía y estudios turísticos. Tan solo se establecieron dos condicionantes: 1 . tipo de publicación, considerándose exclusivamente libros y artículos en revistas científicas, nacionales e internacionales, y 2. La escala de trabajo centrada en España, dentro del marco europeo y de la región mediterránea.

El acceso se ha realizado a través de las webs oficiales de cada revista y de las redes de investigación. En total se han consultado más de un centenar de publicaciones de las que ochenta y nueve están citadas en el texto y en la bibliografía. De ellas la mayoría, $91 \%$, son artículos que corresponden a cuarenta y ocho revistas distintas, de las que el $39,60 \%$ son JCR y el 31,25\% están en Scopus y/o en la Web of Science.

Se observa escasez de trabajos sobre turismo y AVE y algunas de sus causas se desprenden de los artículos previos, referidos en el apartado 4; otras se han corroborado en la investigación realizada por las autoras, que consistió en el estudio de los efectos derivados de la implantación del AVE en ciudades patrimoniales españolas. Para ello se compararon los datos de la Encuesta de Ocupación Hotelera, antes y después de la llegada del AVE, en diferentes ciudades, lo que permite conocer el volumen anual de viajeros y pernoctaciones (nacionales y extranjeros), la duración media de la estancia, el grado de ocupación de los hoteles y la evolución de las plazas hoteleras. Además, se adaptó el modelo gravitatorio de Archer basado en aspectos demográficos y de proximidad, cambiando la variable demográfica por el volumen de viajeros potenciales de cada ciudad (habitantes+turistas). Todo ello ayudó a conocer la realidad de estas ciudades y a identificar algunas de las carencias y problemas que son recogidos en el apartado de discusión.

Figura 1: Revistas analizadas.

\begin{tabular}{|l|c|c|c|c|}
\hline \multicolumn{1}{|c|}{ Nombre de la revista } & Temática / área & $\begin{array}{c}\text { País de } \\
\text { publicación }\end{array}$ & Index & № artículos \\
\hline $\begin{array}{l}\text { Anales de Geografía de la } \\
\text { Universidad Complutense }\end{array}$ & Geografía & España & $\begin{array}{c}\text { WOS- } \\
\text { Scopus }\end{array}$ & 1 \\
\hline Annales de géographie & Geografía & Francia & Scopus & 1 \\
\hline $\begin{array}{l}\text { Belgeo. Revue belge de } \\
\text { géographie }\end{array}$ & Geografía & Bélgica & Scopus & 1 \\
\hline $\begin{array}{l}\text { Boletín de la Asociación de } \\
\text { Geógrafos Españoles }\end{array}$ & Geografía & España & SSCl & 4 \\
\hline
\end{tabular}

Revista de Estudios Andaluces, vol. 34, núm. 1 (2017) pp. 321-349. e-ISSN: 2340-2776 http://dx.doi.org/10.12795/rea.2017.i34.11

\section{c) (i) (9)}




\begin{tabular}{|c|c|c|c|c|}
\hline Business History & $\begin{array}{l}\text { Economía e } \\
\text { historia }\end{array}$ & Reino Unido & $\mathrm{SSCl}$ & 1 \\
\hline Cities & Ciencias Sociales & Reino Unido & $\mathrm{SSCl}$ & 2 \\
\hline $\begin{array}{l}\text { Ciudad, territorio y paisaje: } \\
\text { Reflexiones para un debate } \\
\text { multidisciplinar }\end{array}$ & $\begin{array}{l}\text { Arquitectura, } \\
\text { urbanismo y } \\
\text { geografía }\end{array}$ & España & $\begin{array}{l}\text { WOS- } \\
\text { Scopus }\end{array}$ & 1 \\
\hline $\begin{array}{l}\text { Cuadernos de Ingeniería y } \\
\text { Territorio }\end{array}$ & Ingeniería Civil & España & - & 1 \\
\hline Cuadernos de Turismo & $\begin{array}{l}\text { Turismo, } \\
\text { Geografía }\end{array}$ & España & $\begin{array}{l}\text { WOS- } \\
\text { Scopus }\end{array}$ & 3 \\
\hline Cuadernos geográficos & Geografía & España & $\begin{array}{l}\text { WOS- } \\
\text { Scopus }\end{array}$ & 1 \\
\hline $\begin{array}{l}\text { Environment and Planning } \\
\text { B: Planning and Design }\end{array}$ & Geografía & Reino Unido & $\mathrm{SSCl}$ & 1 \\
\hline $\begin{array}{l}\text { Ería: Revista cuatrimestral } \\
\text { de geografía }\end{array}$ & Geografía & España & wOS & 1 \\
\hline EURE (Santiago) & $\begin{array}{l}\text { Arquitectura, } \\
\text { urbanismo y } \\
\text { geografía }\end{array}$ & Chile & $\mathrm{SSCl}$ & 1 \\
\hline $\begin{array}{l}\text { European journal of regional } \\
\text { development }\end{array}$ & Geografía & $\begin{array}{l}\text { R.Checa, } \\
\text { Hungría y } \\
\text { Serbia }\end{array}$ & - & 1 \\
\hline $\begin{array}{l}\text { European urban and } \\
\text { regional studies }\end{array}$ & $\begin{array}{l}\text { Arquitectura, } \\
\text { urbanismo y } \\
\text { geografía }\end{array}$ & Reino Unido & $\mathrm{SSCl}$ & 1 \\
\hline Geographicalia & Geografía & España & - & 1 \\
\hline $\begin{array}{l}\text { Information Technology } \\
\text { Research Journal }\end{array}$ & $\begin{array}{c}\text { Ciencia y } \\
\text { tecnología de la } \\
\text { información }\end{array}$ & España & $\begin{array}{l}\text { WOS- } \\
\text { Scopus }\end{array}$ & 1 \\
\hline Ingeniería y territorio & Multidisciplinar & España & - & 10 \\
\hline $\begin{array}{l}\text { International Journal of } \\
\text { Sustainable Transport }\end{array}$ & $\begin{array}{c}\text { Tecnología y } \\
\text { Ciencias Sociales }\end{array}$ & $\begin{array}{l}\text { Estados } \\
\text { Unidos }\end{array}$ & $\mathrm{SSCl}$ & 1 \\
\hline Investigaciones Regionales & $\begin{array}{l}\text { Economía y } \\
\text { geografía }\end{array}$ & España & $\begin{array}{l}\text { WOS- } \\
\text { Scopus }\end{array}$ & 2 \\
\hline $\begin{array}{l}\text { Journal of Air Transport } \\
\text { Management }\end{array}$ & $\begin{array}{l}\text { Economía, CC. } \\
\text { Políticas, } \\
\text { Ingeniería Civil e } \\
\text { Industrial }\end{array}$ & Reino Unido & $\mathrm{SSCl}$ & 1 \\
\hline
\end{tabular}

Revista de Estudios Andaluces, vol. 34, núm. 1 (2017) pp.321-349. e-ISSN: 2340-2776 http://dx.doi.org/10.12795/rea.2017.i34.11

\footnotetext{
(c) (i) $(\Theta$
} SinObraDerivada 4.0 Internacional 


\begin{tabular}{|c|c|c|c|c|}
\hline Journal of Choice Modelling & $\begin{array}{l}\text { Estadísticas y } \\
\text { matemáticas }\end{array}$ & Países Bajos & $\mathrm{SSCl}$ & 1 \\
\hline $\begin{array}{l}\text { Journal of transport } \\
\text { economics and policy }\end{array}$ & $\begin{array}{l}\text { CC. Políticas, } \\
\text { economía y } \\
\text { transporte }\end{array}$ & Reino Unido & - & 1 \\
\hline $\begin{array}{l}\text { Journal of Transport } \\
\text { Geography }\end{array}$ & $\begin{array}{l}\text { Biología, } \\
\text { economía, } \\
\text { geografía e } \\
\text { ingeniería } \\
\text { industrial }\end{array}$ & Reino Unido & $\mathrm{SSCl}$ & 5 \\
\hline $\begin{array}{l}\text { Journal of urban planning } \\
\text { and development }\end{array}$ & $\begin{array}{l}\text { Arquitectura, } \\
\text { urbanismo, } \\
\text { economía, } \\
\text { geografía e } \\
\text { ingeniería civil }\end{array}$ & $\begin{array}{l}\text { Estados } \\
\text { Unidos }\end{array}$ & $\mathrm{SSCl}$ & 1 \\
\hline $\begin{array}{l}\text { Les Cahiers scientifiques } d u \\
\text { transport }\end{array}$ & $\begin{array}{c}\text { Transporte y } \\
\text { medio ambiente }\end{array}$ & Francia & - & 1 \\
\hline $\begin{array}{l}\text { Lurralde: Investigación y } \\
\text { espacio }\end{array}$ & Geografía & España & Scopus & 1 \\
\hline Méditerranée & Geografía & Francia & Scopus & 1 \\
\hline $\begin{array}{l}\text { Nimbus: Revista de } \\
\text { climatología, meteorología y } \\
\text { paisaje }\end{array}$ & Geografía & España & - & 1 \\
\hline Papeles de geografía & Geografía & España & - & 1 \\
\hline $\begin{array}{l}\text { Procedia-Social and } \\
\text { Behavioral Sciences }\end{array}$ & $\begin{array}{l}\text { C. Sociales y del } \\
\text { comportamiento }\end{array}$ & $\begin{array}{l}\text { Estados } \\
\text { Unidos }\end{array}$ & - & 1 \\
\hline $\begin{array}{l}\text { Recherche Transports } \\
\text { Sécurité }\end{array}$ & $\begin{array}{l}\text { Economía e } \\
\text { ingeniería }\end{array}$ & Países Bajos & $\begin{array}{l}\text { WOS- } \\
\text { Scopus }\end{array}$ & 2 \\
\hline Regional Studies & $\begin{array}{l}\text { Biología y } \\
\text { geografía }\end{array}$ & Reino Unido & $\mathrm{SSCl}$ & 2 \\
\hline Revista de análisis turístico & $\begin{array}{l}\text { Humanidades y } \\
\text { Ciencias Sociales }\end{array}$ & España & - & 1 \\
\hline $\begin{array}{l}\text { Revista de Economía } \\
\text { Aplicada }\end{array}$ & Economía & España & $\mathrm{SSCl}$ & 5 \\
\hline $\begin{array}{l}\text { Revista de Estudios } \\
\text { Andaluces }\end{array}$ & Geografía & España & WOS & 2 \\
\hline $\begin{array}{l}\text { Revue d'économie Régionale } \\
\text { et Urbaine }\end{array}$ & Economía & Francia & WOS & 1 \\
\hline Revue Géographique de l'Est & Geografía & Francia & - & 1 \\
\hline $\begin{array}{l}\text { Scripta Nova: revista } \\
\text { electrónica de geografía y } \\
\text { ciencias sociales }\end{array}$ & Geografía & España & wOS & 3 \\
\hline
\end{tabular}

Revista de Estudios Andaluces, vol. 34, núm. 1 (2017) pp. 321-349. e-ISSN: 2340-2776 http://dx.doi.org/10.12795/rea.2017.i34.11

(c) (i) (8)

Esta obra se distribuye con la licencia Creative Commons Reconocimiento-NoComercialSinObraDerivada 4.0 Internacional 


\begin{tabular}{|c|c|c|c|c|}
\hline Technovation & $\begin{array}{c}\text { Ciencias naturales, } \\
\text { experimentales y } \\
\text { tecnología en } \\
\text { general, economía } \\
\text { ingeniería } \\
\text { industrial, CC. } \\
\text { Políticas y de la } \\
\text { administración }\end{array}$ & Reino Unido & $\mathrm{SSCl}$ & 1 \\
\hline $\begin{array}{l}\text { The Annals of Regional } \\
\text { Science }\end{array}$ & $\begin{array}{c}\text { Economía, } \\
\text { urbanismo, } \\
\text { Geografía } \\
\text { Medioambiente, } \\
\text { Políticas }\end{array}$ & USA & $\mathrm{SSCl}$ & 2 \\
\hline $\begin{array}{l}\text { The Open Transportation } \\
\text { Journal }\end{array}$ & Transporte & Reino Unido & $\mathrm{SSCl}$ & 1 \\
\hline Transport policy & $\begin{array}{l}\text { Derecho, } \\
\text { economía, } \\
\text { geografía e } \\
\text { Ingeniería } \\
\text { Industrial }\end{array}$ & Reino Unido & $\mathrm{SSCl}$ & 2 \\
\hline Transport Reviews & $\begin{array}{l}\text { Economía e } \\
\text { Ingeniería } \\
\text { Industrial }\end{array}$ & Reino Unido & $\mathrm{SSCl}$ & 2 \\
\hline $\begin{array}{l}\text { Transportation Research } \\
\text { Part A: Policy and Practice \& } \\
\text { Part B: Methodological }\end{array}$ & Ingeniería Civil & $\begin{array}{l}\text { Estados } \\
\text { Unidos }\end{array}$ & $\mathrm{SSCl}$ & 3 \\
\hline $\begin{array}{l}\text { Transportation Research } \\
\text { Record: Journal of the } \\
\text { Transportation Research } \\
\text { Board }\end{array}$ & $\begin{array}{c}\text { Geología, } \\
\text { ingeniería y } \\
\text { medioambiente }\end{array}$ & $\begin{array}{l}\text { Estados } \\
\text { Unidos }\end{array}$ & - & 1 \\
\hline Transporte y territorio & Geografía & Argentina & - & 1 \\
\hline
\end{tabular}

Fuente: Elaborado por Aida Pinos y Carmen Mínguez, a partir de las webs oficiales de cada revista y de MIAR (http://miar.ub.edu/).

\section{RESULTADOS: LA MULTIDISCIPLINARIEDAD COMO RASGO PRINCIPAL DE LAS INVESTIGACIONES CIENTÍFICAS SOBRE LA ALTA VELOCIDAD ESPAÑOLA}

\subsection{LA INVESTIGACIÓN DE LA ALTA VELOCIDAD DESDE LA ECONOMÍA}

Los economistas españoles han generado una nutrida producción con la que han intentado comprobar, entre otras cuestiones, la rentabilidad social y productiva de la elevada inversión pública en infraestructuras dedicada a la alta velocidad. En relación

Revista de Estudios Andaluces, vol. 34, núm. 1 (2017) pp.321-349. e-ISSN: 2340-2776 http://dx.doi.org/10.12795/rea.2017.i34.11

\section{(c) (i) $(\Theta$}


con ello resulta necesario evaluar sus ventajas y conocer su tasa de retorno social teniendo en cuenta los costes, los beneficios y el volumen de demanda inicial. Autores como Álvarez-San Jaime y Herce (1993), Albalate y Bel (2011), Bel (2011), Gutiérrez et al (2015) o Álvarez-San Jaime et al (2016) han abordado la evaluación económica de la infraestructura a nivel general, relacionándola incluso con el bienestar y la cohesión social, como hicieran Adler et al (2010) en 27 países de la Unión Europea, incluido España, mientras que otros han trabajado situaciones concretas. Este es el caso de Rus e Inglada (1993) que estudiaron el AVE Madrid-Sevilla, Rus y Román (2006) que se centraron en el AVE Madrid-Barcelona y Sánchez-Ollero et al., (2014) quienes analizaron la red andaluza, principalmente, Sevilla y Málaga.

Dentro de los estudios de caso destacan los que analizan los costes-beneficios (Rus e Inglada, 1997; Boscá, et al., 2011; Coto et al, 2007). Estos autores señalan, entre otras ideas, que la red española transporta un volumen de viajeros muy bajo si se compara con Japón o Francia, países que tienen una extensión similar (Sánchez-Ollero et al., 2014). Por tanto, coinciden en que existe una sobrevaloración de los efectos positivos de la infraestructura, los cuales alimentan el discurso oficial, a pesar de que los resultados científicos evidencien lo contrario. Además, apuntan que se produce una disparidad de los beneficios y una concentración en aquellas regiones con mayor poder adquisitivo. Así, en la mayoría de las ocasiones, el establecimiento de las líneas obedece a intereses consensuados políticamente, lo que conlleva que la relación coste-beneficio no siempre resulte positiva ni responda a una lógica geoespacial justificada (SánchezOllero, 2014; Albalate y Bel, 2011).

En los últimos años, los economistas están dedicando especial atención al análisis de la competencia entre distintos modos de transporte (González-Savignat, 2004a, 2004b; Román et al, 2007; Pagliara et al, 2012) como el vehículo privado o el avión desde el punto de vista del usuario. Esta cuestión resulta clave en la toma de decisiones sobre proyectos de inversiones públicas, pues se trata de conocer el comportamiento de la demanda en un determinado espacio geográfico para elegir el modo de transporte en el que viajar. La disponibilidad del consumidor a pagar por un transporte u otro varía en función de una amplia gama de variables como: confort, fiabilidad, tiempo en el destino, probabilidad de retraso y tiempos de acceso y espera (González-Savignat, 2004a, 2014b), siendo lo más importante, según Pagliara et al, los precios y la frecuencia del servicio. Además, la presencia de controles de seguridad tiene cada vez mayor importancia en esta elección (Pagliara et al, 2012).

Con las preferencias reveladas y conociendo las características de la alta velocidad, se realizan aproximaciones hipotéticas de la elección del usuario por distintos medios de transporte en diferentes contextos y en función de su perfil. Por ejemplo, en el caso del análisis de la demanda del AVE sobre otras modalidades de transporte en el corredor Madrid-Zaragoza-Barcelona (Román et al, 2010), se determina que el tren puede ejercer una competencia importante con el coche en el tramo Madrid-Zaragoza pero que en el caso del trayecto Madrid-Barcelona puede perder usuarios frente al avión. En esta línea

Revista de Estudios Andaluces, vol. 34, núm. 1 (2017) pp. 321-349. e-ISSN: 2340-2776 http://dx.doi.org/10.12795/rea.2017.i34.11 
se evalúan los impactos microeconómicos esperados con las inversiones previstas en el Plan de Infraestructuras 2000-2010, teniendo en cuenta las inversiones en carretera y la oferta aérea, y se prevé un importante crecimiento del mercado de la alta velocidad (Martín y Nombela, 2007).

\subsection{LA INVESTIGACIÓN DE LA ALTA VELOCIDAD DESDE LAS INGENIERÍAS}

Los profesionales de la ingeniería, especialmente en Caminos, Canales y Puertos y en Ingeniería Civil, han contribuido a la producción científica con análisis de la situación actual y de los retos de futuro de la red de alta velocidad europea (Garmendia et al., 2012). Sus contribuciones abordan los siguientes aspectos:

El primero de ellos ofrece una visión general de los impactos territoriales de la alta velocidad a nivel internacional (Rodríguez et al., 2005). Se afirma que este sistema de transporte tiene algunas limitaciones, por lo que necesita estrategias de desarrollo complementarias. Además, en ocasiones, su implantación en sustitución de la red ferroviaria tradicional puede resultar contraproducente para lograr una accesibilidad uniforme e interconectada territorialmente. No obstante, la alta velocidad también tiene efectos positivos en el transporte regional e interregional (López, 2005). Esta puede ser un nexo de unión importante entre ciudades que anteriormente no tenían ninguna conexión, dando lugar a una vertebración del territorio más completa y compleja. Esto sucede, por ejemplo, en el interior de Cataluña donde se han establecido enlaces regionales e interregionales con la Comunitat Valenciana, Aragón o Pirineos.

La segunda cuestión también está relacionada con la ordenación del territorio y más concretamente con el tratamiento de la alta velocidad ferroviaria en los planes de infraestructuras y transporte (Guirao y Menéndez, 2005), como el Plan Estratégico de Infraestructuras y Transporte (2005-2020). En este caso se trata la evolución del concepto de alta velocidad ferroviaria, la complementariedad del servicio con la red tradicional y el nuevo escenario que plantea el PEIT. Se concluye con la idea de que la calidad de la oferta está vinculada a la reducción en los tiempos de viaje $y$, sobre todo, a un régimen de frecuencia equilibrado a la demanda existente en cada parada.

El tercer tema analizado ha sido la desigual accesibilidad y los efectos en la movilidad (Menéndez et al., 2002; Coronado y Rivas, 2005). En el primer caso, los autores señalan que las redes transeuropeas deben mejorar la cohesión económica y social de Europa, especialmente de aquellas regiones más desfavorecidas. Sin embargo, la realidad es que tan sólo se conectan los principales centros económicos incrementando las diferencias territoriales en el continente y dando lugar a "regiones centrales" y "regiones periféricas". En el segundo caso, se aborda la movilidad (demanda, pautas y perfil de los usuarios) en Ciudad Real y Puertollano, ciudades pequeñas a una hora de Madrid. Se concluye señalando que la alta velocidad supuso en este corredor una reducción de los

Revista de Estudios Andaluces, vol. 34, núm. 1 (2017) pp.321-349. e-ISSN: 2340-2776 http://dx.doi.org/10.12795/rea.2017.i34.11

\section{(c) (i) (3)}

SinObraDerivada 4.0 Internacional 
costes de transporte y, vinculado a ello, un aumento en el número de desplazamientos; especialmente, de movimientos pendulares realizados a la capital por parte de commuters y estudiantes.

Es interesante la visión espacial con la que analizan los efectos de la red para las ciudades del continente europeo (relaciones entre núcleos urbanos, efectos espaciales e importancia de las estaciones). En esta línea se estudian las dinámicas territoriales generadas por el AVE (Ureña, 2005, Ureña et al., 2009) que favorecen la descentralización, ya que las mejoras de la accesibilidad permiten la integración de pequeñas ciudades en los procesos metropolitanos. Del análisis de Toledo, Zaragoza y Córdoba se deriva que las decisiones obedecen más a criterios inmobiliarios que a la intención de atraer nuevas actividades, al tiempo que se observa una relación entre la ubicación de la residencia, respecto a la estación y el tipo de habitante (local-inmigrante; propietario-inquilino...) (Garmendia et al, 2008).

Por último, algunos ingenieros han centrado sus estudios en la competitividad de la alta velocidad ferroviaria frente a otros medios como el transporte por carretera, en el Eje Transversal Andaluz (Calvo y de Oña, 2005) y el vehículo privado (Moyano et al., 2016). Así, se determina que el AVE en la región andaluza puede resultar altamente competitivo si se acompaña de estrategias de actuación y coordinación promovidas por los responsables ferroviarios. Además, se plantea que pueda convertirse en un transporte alternativo al coche para el turismo de fin de semana. Para ello se desarrolla el cálculo de un indicador de eficiencia basado en el tiempo disponible en el destino y los costos asociados al viaje. Así, para los viajes de corta distancia el uso del tren o vehículo privado estaría en función del número de pasajeros que se desplacen al destino pues, con cuatro ocupantes, los costos de viaje en automóvil son menores que los que supondría viajar en otro medio; sin embargo, en trayectos de media o larga distancia, la alta velocidad ferroviaria aumenta su nivel de competitividad.

\subsection{LA INVESTIGACIÓN DE LA ALTA VELOCIDAD DESDE LA GEOGRAFÍA}

Los geógrafos han encontrado en la alta velocidad un excelente campo de estudio, lo que les ha llevado a ser uno de los colectivos que más producción científica han generado, abordando diferentes temáticas.

La primera acomete el estudio de la evolución de la red, sus perspectivas futuras (Serrano, 2000 y 2004; Martí-Henneberg, 2013; Martín, 2013) y la definición y caracterización de alta velocidad (Givoni, 2006). Estos autores estudian la red del AVE desde una dimensión supranacional y tratan de realizar una propuesta "ambiciosa" encaminada a lograr una mayor conectividad a nivel peninsular y europeo. Por tanto, se propone construir una nueva red sin renovar la antigua e intentando adaptarla a las necesidades y dinámicas territoriales, a los recursos humanos y a las ciudades españolas (Serrano, 2000). El proceso es complejo pues no existe una red que vertebre el territorio europeo y hay cierta descoordinación-intereses dispares en las políticas de transporte

Revista de Estudios Andaluces, vol. 34, núm. 1 (2017) pp. 321-349. e-ISSN: 2340-2776 http://dx.doi.org/10.12795/rea.2017.i34.11 
de los estados miembros. Un ejemplo lo constituyen los países de la Península Ibérica y Francia, pues los Pirineos suponen un obstáculo para las comunicaciones (Serrano, 2004). Givoni (2006) además afirma que la alta velocidad ferroviaria ha consolidado de nuevo al tren como un modo de transporte de pasajeros, competitivo en trayectos en los que se requiere alta capacidad y tiempo de viaje reducido frente al ferrocarril tradicional. No obstante, señala que la elevada inversión que necesita no siempre está justificada.

Martí-Henneberg (2013) analiza la evolución de los ferrocarriles en los diferentes países de Europa desde la segunda mitad del siglo XIX para comprender mejor los retos futuros de alta velocidad actual. Según se deriva de este estudio, en el que utilizaron los SIG, el transporte ferroviario siempre ha estado sujeto a decisiones estatales y no tanto a ordenanzas comunitarias. Por su parte, Martín (2013) realiza un estudio de la red del AVE utilizando un modelo gravitatorio (el modelo de Archer). Con él pretende mostrar la relación entre la expansión de la red y el número de viajeros que la utiliza, partiendo del volumen demográfico y las distancias espaciales que separan las ciudades. Así, se identifican corredores con un tráfico de pasajeros importante, como Madrid-Barcelona o Madrid-Valencia, y otros con ciertas limitaciones como Madrid-Albacete o MadridTarragona.

El segundo gran tema analizado por los geógrafos son los efectos espaciales y socioeconómicos que conlleva la implantación y servicio de la infraestructura. Esta es una de las líneas sobre las que se ha aportado un mayor número de publicaciones (Gutiérrez, 2004; González et al, 2005; Santos y de las Rivas, 2005; Bellet y Llop, 2005; Alonso y Bellet, 2009; Serrano et al., 2010; Soria, 2010; Bellet et al, 2010, 2012; Bellet y Gutiérrez, 2011; Bellet, 2013). Todos los autores coinciden en afirmar que la alta velocidad genera efectos espaciales y socioeconómicos en las ciudades, como la competencia, y en el territorio, como la integración o el "efecto túnel". Sin embargo, son efectos polarizadores, pues se trata de un sistema de transporte muy selectivo (Gutiérrez, 2004). Los territorios por los que discurren los trazados viarios están sometidos a un importante riesgo de fragmentación espacial (Serrano et al., 2010), mientras que las ciudades son las que reciben las consecuencias más importantes de la llegada de la alta velocidad. El nivel de impacto en muchas ocasiones está relacionado con su tamaño poblacional y jerarquía urbana (González et al, 2005).

La instauración de la alta velocidad en distintas ciudades del territorio nacional (Ciudad Real, Figueres, Valladolid, Córdoba, Lleida...) ha sido percibida como un instrumento de desarrollo socioeconómico, al afectar a su población y a su actividad económica, suponiendo un impulso para el desarrollo de nuevas actividades (González et al., 2005). En el caso concreto de Ciudad Real ha derivado un incremento de su relevancia a nivel provincial y en un papel de intermediación entre la provincia y las grandes áreas urbanas más alejadas (Garmendia et al., 2011). Pero también es considerada como un 
instrumento urbanístico, ya que actúa como motor de desarrollo de nuevo tejido urbano y permite cambios en los usos del suelo de aquellos espacios que quedan libres por el traslado de sus instalaciones (González et al., 2005). En el caso concreto de Valladolid se buscaba un profundo cambio urbanístico y funcional ante la llegada del AVE, pues veía en ella la oportunidad para llevar a cabo una transformación espacio-funcional (Santos y de las Rivas, 2005). La inauguración del primer tramo del Corredor Noroeste trajo consigo una idea generalizada de posibilidad de cambio en el medio urbano. El soterramiento del ferrocarril implicó el surgimiento de una nueva centralidad a la par que nuevos espacios residenciales e industriales; transformaciones que además de una fuerte inversión necesitan la coordinación de los distintos agentes territoriales implicados (Soria, 2010). Por tanto, se valora la alta velocidad como una oportunidad para transformar la ciudad, con capacidad de obtener dinámicas socioeconómicas y espaciales positivas, siempre que se ajusten al modelo urbano de cada ciudad (Bellet y Llop, 2005; Santos y de las Rivas, 2005; Alonso y Bellet, 2009; Bellet et al, 2010, 2012; Bellet y Gutiérrez, 2011).

La tercera temática se centra en el impacto de las líneas de alta velocidad en la accesibilidad a escala europea (Gutiérrez et al, 1996; Gutiérrez, 2001; Pueyo et al., 2012). Fue iniciada por Gutiérrez et al., en 1996, utilizando los SIG como herramienta de análisis. En ese trabajo afirmaron que estas líneas modifican la accesibilidad, pues reducen las distancias acercando aquellas regiones periféricas a las centrales. Por ello, la red transeuropea resulta beneficiosa a nivel general y a las regiones periféricas en particular (Gutiérrez et al, 1996). Posteriormente, con la misma metodología y herramienta se analizó la accesibilidad en la línea Madrid-Barcelona-frontera francesa y para ello se usaron tres indicadores: 1. tiempo de viaje, 2. potencial económico y frecuencia al día para determinar la accesibilidad e 3. información complementaria. Las conclusiones mostraban que el impacto depende de la escala de análisis, ya que, a nivel nacional y en el Corredor Noreste se observaba una polarización, mientras que a escala europea se daba un mayor equilibrio (Gutiérrez, 2001; Pueyo et al., 2012). Gutiérrez Puebla, junto con los economistas Concepción Román y Juan Carlos Martín (2004) han tratado de avanzar en el conocimiento de este corredor midiendo los impactos de la accesibilidad a las nuevas infraestructuras a través del Data Envelopmet Analysis (DEA), un índice compuesto de accesibilidad que permite una mejor comprensión de los cambios generales y los efectos derivados de la polarización y el equilibrio territorial (Martín et al, 2004).

El cuarto gran tema afronta el análisis de los efectos espaciales de las estaciones (Facchinetti-Mannone, 2005), sus características en términos de intermodalidad (Tapiador et al., 2009) y el modo de acceso a estas (Burckhart et al., 2008). Según Facchinetti-Mannone (2005) las estaciones de alta velocidad ubicadas en la periferia de pequeñas ciudades no favorecen la ordenación del territorio ya que estos nodos no son capaces de crear nuevas dinámicas territoriales y se convierten en simples puntos de subida o bajada de pasajeros, sin repercusiones positivas en el entorno inmediato. Para su estudio Tapiador et al. (2009) aplicaron un método cuantitativo que les permitió

Revista de Estudios Andaluces, vol. 34, núm. 1 (2017) pp. 321-349. e-ISSN: 2340-2776 http://dx.doi.org/10.12795/rea.2017.i34.11 
compararlas, mejorar su rendimiento y obtener un modelo integral aplicable a escalas inferiores. Así, comprobaron que existe una importante jerarquización de las estaciones a nivel europeo en relación con sus funciones. Ante la ausencia de datos sobre el acceso de los viajeros a la estación, Burckhart et al., (2008) diseñaron encuestas para los usuarios de la línea Madrid-Barcelona y como conclusiones obtuvieron que generalmente se recurre al vehículo privado para llegar a la estación y que sería conveniente ofrecer otras alternativas de acceso. Además, los usuarios prefieren las estaciones céntricas y estas resultan más sostenibles en términos de movilidad.

El quinto tema estudiado desde la Geografía es la evolución de la demanda de la alta velocidad y las características de sus viajeros (González et al., 2005; Santos et al., 2006). En España la demanda de estos servicios ha experimentado un crecimiento en las dos últimas décadas; evidencia de ello es el paulatino incremento de usuarios en la línea Madrid-Sevilla, que llega a transportar al $80 \%$ de los viajeros desde la capital a la ciudad andaluza. En 2002, en torno a 43 millones de personas se habían desplazado en AVE, correspondiendo aproximadamente 6 millones al trayecto Madrid-Sevilla. No obstante, la demanda de usuarios ha experimentado fluctuaciones, observándose máximos en primavera y otoño y mínimos en verano e invierno (González et al., 2005; Santos et al., 2006).

Las ventajas del AVE atraen a un público variado, que ha vivido un proceso de diversificación importante, en cuanto a sus motivaciones y perfiles. Se aprecian diferencias entre los usuarios de largo recorrido y los de trenes lanzadera. En el primer caso, los pasajeros presentan un perfil socioeconómico más elevado (directivos, empresarios, agentes comerciales...) y se desplaza por motivos profesionales o turismo ocasional; en el segundo, el nivel socioeconómico es inferior (administrativos, estudiantes, amas de casa, jubilados...) y sus viajes son prácticamente diarios y obedecen a motivos laborales, estudios, razones médicas o familiares (González et al., 2005; Santos et al., 2006).

El sexto tema, también trabajado desde otras disciplinas, es la competencia entre la alta velocidad ferroviaria y otras modalidades de transporte como el aéreo (Dobruszkes, 2011, Díez, 2012a; Díez y Sánchez, 2012; Dobruszkes et al., 2014); así como la comparativa de los impactos de distintas modalidades (Givoni, 2007). Precisamente, el transporte aéreo tiene un importante impacto medioambiental por lo que los autores señalan al tren como una buena alternativa (Givoni, 2007; Díez, 2012a; Dobruszkes, 2011, Dobruszkes. et al., 2014). Sin embargo, desde el punto de vista de la oferta, la alta velocidad presenta limitaciones respecto al avión ya que algunas compañías aéreas reducen el número de plazas y aumentan la frecuencia lo que las convierte en más competitivas. Además, las compañías aéreas de bajo coste también representan una amenaza evidente para el nuevo ferrocarril (Dobruszkes, 2011). No obstante, cuando los trayectos son cortos, la alta velocidad resulta más competitiva y a medida que el viaje

Revista de Estudios Andaluces, vol. 34, núm. 1 (2017) pp.321-349. e-ISSN: 2340-2776 http://dx.doi.org/10.12795/rea.2017.i34.11

\section{(c) (i) (3)}

SinObraDerivada 4.0 Internacional 
en tren se aproxima a las 2 horas ó 2:30 de duración, el avión se convierte en una potencial amenaza (Dobruszkes et al., 2014). En este sentido, Givoni (2007) realizó un estudio en el que se comparaba el impacto ambiental (contaminación del aire y efectos sobre el cambio climático) de una plaza de avión y una de tren en el trayecto LondresParís. Los resultados que se derivan de la investigación muestran que la alta velocidad resulta más beneficiosa para el medio ambiente que el empleo del avión.

La última temática, estudiada de forma exclusiva desde la geografía, relaciona la alta velocidad con la gobernanza territorial, el papel de los agentes implicados y las medidas de gestión adoptadas (Casellas et al., 2011; Feliú, 2012; Bellet et al., 2010, 2012). Los autores que la han trabajado coinciden en que es absolutamente necesaria la colaboración de los distintos agentes territoriales cuando se implanta la alta velocidad en un determinado espacio y que las decisiones relativas a la ubicación de la estación deben ser tomadas en consenso con los ciudadanos y han de estar en consonancia con factores propios de la infraestructura, pero también con otros vinculados al modelo local (Ribalaygua, 2005). Así, los distintos agentes locales y redes socio-institucionales deben cooperar entre sí pues, aunque sus situaciones sean diferentes, tienen un objetivo en común: el correcto funcionamiento de la alta velocidad en su territorio (Casellas et al., 2011). La existencia o ausencia de un grupo de actores locales que se organicen entre ellos determina en gran medida el éxito o fracaso del nuevo ferrocarril y las actuaciones y estrategias requieren una continuidad y están sujetas a transformaciones que garanticen la máxima eficiencia en todos los ámbitos de la realidad territorial. Cecilia Ribalaygua (2005), ingeniera y profesora del área de Geografía Humana del Dpto. de Geografía, Urbanismo y Ordenación del Territorio de la Universidad de Cantabria, señala que es fundamental que las ciudades a las que llega la red establezcan estrategias previamente. Además de las medidas de previsión, remarca la necesidad de otras relacionadas con la gestión y promoción que vinculen el núcleo con diferentes regiones en unos horarios y frecuencias adecuados, al tiempo que, se realiza la difusión necesaria. Todas estas medidas deben ser lanzadas desde el ámbito supramunicipal y requieren la coordinación intramunicipal para garantizar un desarrollo equilibrado.

Feliú (2012) analizó los casos de tres ciudades medias diferentes y alejadas espacialmente: Lleida (España), Avignon (Francia) y Novara (Italia), llegando a la conclusión de que en ellas existía una escasa colaboración entre los actores locales, una baja participación ciudadana en las decisiones relacionadas con el desarrollo local y algunos conflictos a múltiples escalas. Este contexto, con carencias de gestión a nivel interno y externo, se limitaba el aprovechamiento de los recursos endógenos en la localidad (en este caso la llegada de la alta velocidad).

Bellet et al. (2010, 2012) hacen alusión a la necesidad de políticas y acciones paralelas a la alta velocidad. Estas son de tres tipos: 1. medidas de planificación para integrar la infraestructura de forma eficiente en el medio; 2 . medidas de gestión para adaptar los flujos y movilidades que se generen y consolidar la centralidad de la estación; y 3. medias de promoción e imagen urbana asociadas a campañas de marketing territorial.

Revista de Estudios Andaluces, vol. 34, núm. 1 (2017) pp. 321-349. e-ISSN: 2340-2776 http://dx.doi.org/10.12795/rea.2017.i34.11 


\section{ESTUDIOS SOBRE LA INFLUENCIA DE LA RED DE ALTA VELOCIDAD ESPAÑOLA Y EL TURISMO}

\subsection{EL FERROCARRIL ESPAÑOL EN LA ACTIVIDAD TURÍSTICA ESPAÑOLA ACTUAL}

En España, al igual que en otros países, la apertura de la primera línea de alta velocidad supuso el paso definitivo hacia un nuevo modelo de desplazamientos y comunicaciones del que no escapa la actividad turística. Pese a los inconvenientes, abordados en los puntos anteriores, los agentes territoriales de diferentes regiones han visto en esta modalidad de transporte una serie de oportunidades no solo para sus residentes sino también para sus empresas, incluidas las del sector turístico, que parecer ser los más beneficiados (Albate y Bel, 2011).

La relación transporte-turismo y la necesidad mutua es evidente. Así, estas redes tienen un doble papel: salvar la distancia entre dos nodos (emisores y receptores de turistas) y facilitar la accesibilidad y la movilidad, lo cual resulta determinante en la elección del destino turístico (Moyano et al., 2016). En relación con lo anterior, en gran cantidad de ocasiones, el atractivo turístico de un destino depende de factores relacionados con el sistema de transporte como los tiempos de viaje, horarios, coste del billete, posibilidades de complementariedad intermodal, etc. Evidentemente, a estos se suman los relacionados con el propio destino: precios de alojamiento, comidas, alternativas de ocio y/o descanso, etc. (Delaplace et al., 2014; Moyano et al., 2016).

En este sentido, el tren de alta velocidad reduce los tiempos y costos de transporte y mejora la accesibilidad, por lo que constituye una herramienta potencial para impulsar el desarrollo turístico de distintas ciudades (Masson y Petiot, 2009). Sin embargo, según los informes de coyuntura de FAMILITUR, en España existen importantes desequilibrios en el uso de los diferentes sistemas de transporte: el vehículo privado supone el $84 \%$ de los desplazamientos frente al tren, autobús y avión que tan sólo cubren un $5 \%$ de los viajes. Esta clara hegemonía del uso del coche está relacionada con factores como no tener que depender de horarios establecidos para iniciar el viaje, la necesidad de hacer uso del vehículo en el destino o los reducidos gastos, máxime si se trata de desplazamientos en grupos de más de tres individuos. No obstante, los costes derivados del mantenimiento, seguros, etc., así como las dificultades y coste del aparcamiento del vehículo privado también son elementos a considerar que reducen su competitividad (Moyano et al., 2016). Ante esta situación, la operadora ferroviaria española (RENFE) está reorientando sus servicios hacia el mercado turístico para competir con otros sistemas de transporte, principalmente el vehículo privado. De esta forma, se persigue que el AVE se convierta en una alternativa para los viajes de fin de semana (Moyano et al., 2016) que, según FAMILITUR, representan alrededor del $55 \%$ de los desplazamientos turísticos en España.

Revista de Estudios Andaluces, vol. 34, núm. 1 (2017) pp.321-349. e-ISSN: 2340-2776 http://dx.doi.org/10.12795/rea.2017.i34.11 
Las nuevas estrategias comerciales de RENFE se basan en diversificar la oferta de servicios, aplicar descuentos y ofrecer paquetes turísticos para atraer viajeros, todo con el objetivo de aumentar el nivel de ocupación de los trenes con precios más rentables a los de otras modalidades de transporte. En 2013, implantaron el producto "AV City" para ofrecer precios más económicos y facilitar e incrementar la movilidad en las horas de menor actividad. De esta forma, el precio de los billetes se reducía hasta un $70 \%$ en función de los horarios, posibles conexiones y la antelación con la que se adquiriesen (Moyano et al., 2016). El resultado de este servicio fue un aumento de viajeros de un $23 \%$ y un $12 \%$ más de ocupación (RENFE, 2014).

La compañía ferroviaria introdujo dos nuevos servicios: "Spain Pass" y "Avexperience". El primero está dirigido a los turistas extranjeros que pueden viajar a algunas ciudades del AVE sin limitaciones; el segundo incluye desplazamientos entre dos ciudades unidas por la alta velocidad, alojamiento en hoteles y descuentos en museos, restaurantes, transportes, durante los fines de semana. Por tanto, la alta velocidad ha revolucionado el sector turístico al incrementar el atractivo de los destinos abaratando los costes de desplazamiento y mejorando la accesibilidad. Por todo ello, se puede afirmar que se está convirtiendo en una opción de transporte que puede resultar muy productiva para generar dinámicas territoriales si se complementa con la planificación turística de cada ciudad. Precisamente, estas se han agrupado en una Red de Ciudades del AVE, fundada en 2006, que permite la colaboración conjunta, especialmente para la promoción y el intercambio de experiencias (García, 2007).

\subsection{LA INVESTIGACIÓN DE LA ALTA VELOCIDAD Y EL TURISMO DESDE UN ENFOQUE MULTIDISCIPLINAR}

Este campo de trabajo no es exclusivo de una disciplina. Los economistas han estudiado los impactos de la alta velocidad en el plano socioeconómico en relación con el sector turístico (Masson y Petiot, 2009) y en términos de movilidad. En estos casos se concluye diciendo que el efecto no se corresponde con el esperado inicialmente, aunque la ausencia de retornos económicos se justifica alegando cohesión social, beneficios medioambientales y desarrollo económico (Sánchez-Ollero et al., 2014). No obstante, confirman que el AVE puede tener un papel clave en el desarrollo de un destino turístico, puesto que este sistema de transporte permite mejorar la accesibilidad y reducir los tiempos de viaje. Sin embargo, la potenciación de varios destinos da lugar a una situación de competencia espacial y a una aglomeración de las actividades en aquellos lugares en los que el coste de transporte es más reducido. Así, en la línea entre Perpignan (Francia) y Barcelona (España), la concentración de actividades turísticas puede favorecer la afluencia a la ciudad española en detrimento de la francesa que debería buscar estrategias de diferenciación (Masson y Petiot, 2009).

Por su parte, Sánchez-Ollero et al. (2014) señalan que Sevilla parece haber llegado a su límite de cuota de mercado y Málaga puede encontrar en la apertura de la línea MadridValencia un duro competidor de turistas de sol y playa procedentes de un importante

Revista de Estudios Andaluces, vol. 34, núm. 1 (2017) pp. 321-349. e-ISSN: 2340-2776 http://dx.doi.org/10.12795/rea.2017.i34.11

c) (i) $\Theta($

c) SinObraDerivada 4.0 Internacional 
foco emisor, Madrid. Además, como sucede con los desplazamientos generales las nuevas líneas de alta velocidad ferroviaria pueden alterar también la movilidad turística y su impacto está ligado a las variables de distancia, tiempo y perfil del viajero y del viaje. En trayectos de larga distancia, el tren resulta competitivo en relación al autobús y al avión, pero si el recorrido es más corto este puede atraer a los usuarios del automóvil que convertirían la alta velocidad en su modo de transporte habitual (Martín y Nombela, 2008). Por otra parte, en la elección del medio de transporte para viajes turísticos de fin de semana está condicionada por el tiempo disponible en el destino, los horarios y tiempos de viaje y los gastos totales de la estancia.

En el año 2013, Coronado et al. se cuestionaron la utilidad de la red de alta velocidad para los viajes turísticos de tan sólo un día de duración. Esta investigación llegó a una conclusión obvia que señalaba que el grado de utilidad es variable dependiendo de la ciudad de destino, aunque como las líneas convergen en Madrid las ciudades más "aptas" para practicar este tipo de turismo son las que están próximas a este punto y tienen conexión con la capital. Sin duda, las condiciones de accesibilidad que ofrece la alta velocidad hace que sea una opción competitiva, que se ve reforzada con la reducción de las tarifas planteadas por RENFE (Moyano et al, 2016).

A pesar de que el turismo está muy bien estudiado por los geógrafos españoles, dando lugar a una línea de trabajo fecunda, que es la Geografía del Turismo y a que hay importantes grupos en las universidades de las ciudades afectadas, son muy pocas las aportaciones realizadas en este campo. Destaca tan solo los trabajos de Víctor Esteban (1998), Esther Gil (2010) y Òscar Saladié et al (2016). El primero de ellos aborda el estudio comparando los impactos de la alta velocidad española y francesa, y se centra en la localización del sector terciario en relación con las estaciones. En este contexto afirma que este medio de transporte favorece el desplazamiento de turistas, al tiempo que destaca la falta de información estadística y como esto dificulta su estudio. Además, señala que el AVE beneficia a determinadas formas de turismo (negocios y ferias, especialmente), al tiempo que lo responsabiliza de ser una de las causas de reducción de la pernoctación, junto con la crisis económica y las mejoras en otros medios de transporte (Esteban, 1998).

En el segundo se analiza la posible incidencia de la línea Madrid-Segovia-Valladolid sobre la actividad turística de la ciudad segoviana. Se concluye señalando que este destino resultará beneficiado con la llegada de la nueva infraestructura, al experimentar el "efecto llamada" característico de los primeros meses, que conlleva una posible intensificación del excursionismo y un dinamismo en el sector de la restauración y la hostelería. Se puede afirmar que el papel de los distintos agentes resulta clave para favorecer y consolidar el crecimiento del sector turístico fruto de la nueva oportunidad que supone el AVE (Gil, 2010). Si bien sería interesante realizar un análisis después de la implantación del AVE para comparar si los efectos se asemejan a los esperados.

Revista de Estudios Andaluces, vol. 34, núm. 1 (2017) pp.321-349. e-ISSN: 2340-2776 http://dx.doi.org/10.12795/rea.2017.i34.11

\section{c) (i) (\$)}

SinObraDerivada 4.0 Internacional 
En el tercero trabajo los autores estudian las repercusiones de la llegada del AVE a Tarragona y más concretamente su vinculación con la elección de la Costa Dorada como destino. Para ello diferencian entre los turistas que viajan por primera vez, para quienes sí es determinante la presencia del AVE, y los repetidores, que se ven menos afectados por este motivo y más condicionados por la inercia, la rutina o el apego al lugar. Destacan que sería interesante replicar esta metodología en otros destinos y usar los resultados en las estrategias de promoción de los destinos (Saladié et al, 2016).

\section{DISCUSIÓN}

El análisis realizado demuestra que en España la relación entre el AVE y el turismo ha sido poco investigada; algo que, por ejemplo, no sucede en Francia, donde habitualmente se realizan informes administrativos y científicos. En ellos se analiza el impacto del Train à Grande Vitesse (TGV) en la actividad turística de diferentes ciudades y en relación con diferentes tipos de turismo y con las estrategias de desarrollo (Bazin et al, 2010 y 2013). De ellas se desprende que, pese a que las repercusiones del TGV son muy importantes, especialmente para el turismo urbano y de negocios, estas son consideradas secundarias, ya que hay otros factores todavía más importantes (presencia de clientes, voluntad política, renovación de productos...). En esta línea, Bazin et al., (2014) estudiaron cómo el TGV convierte a las ciudades situadas en un radio de 1:30 horas de París, como Reims, Metz o Tours, entre otras, en destinos de fin de semana para los parisinos y turistas que visitan la capital. En este contexto, existe el riesgo de que se pueda producir un deterioro medioambiental y una reducción de la estancia habitual en cada una de ellas. Precisamente, para la evitar la reducción del viaje resulta esencial la coordinación entre las ciudades, generando multidestinos en el entorno de París (Bazin-Benoit y Delaplace, 2015) y se están desarrollando estrategias de revalorización de sus recursos, consecuencia del interés creciente por mejorarlos y conservarlos, así como por proyectar una imagen mejorada de la ciudad.

Estos planteamientos son de gran interés en España y hasta la fecha no han sido abordados, pese a que favorecerían la comprensión de algunos de los procesos territoriales e impactos estudiados. Además, ayudarían a establecer estrategias de promoción de los destinos, según segmentos turísticos y diferentes tipos de visitantes. Atendiendo a lo que manifiestan algunos de los autores y a la investigación desarrollada, se consideran diferentes causas que explican el escaso desarrollo de esta línea de investigación: 1. la falta de información oficial, puesto que no existen datos desagregados de RENFE que hagan referencia al perfil de los viajeros ni a sus motivaciones. 2. en relación con lo anterior, la ausencia de fuentes específicas que permitan estudiar esa relación y el uso de fuentes turísticas diseñadas con otros fines (Encuesta de Ocupación Hotelera, Consultas a las Oficinas de Información Turística, acceso a los monumentos y museos...). 3. la relevancia que adquiere el excursionismo, fenómeno de difícil cuantificación y conocimiento. 4. el hecho de que las dinámicas turísticas se ven marcadas por numerosos y diversos factores (recursos, agentes,

Revista de Estudios Andaluces, vol. 34, núm. 1 (2017) pp. 321-349. e-ISSN: 2340-2776 http://dx.doi.org/10.12795/rea.2017.i34.11 
estrategias...), lo que hace que el medio de transporte elegido sea una de las múltiples variables a tener en cuenta. 5 . la actividad turística se ha visto fuertemente afectada en los últimos años por la crisis económica. Esto ha repercutido directamente en los desplazamientos realizados en un transporte considerado caro, pero también ha afectado a los destinos, alterando los datos de coyuntura turística, que son una de las fuentes de estudio. De manera que el fuerte impacto de la crisis ha distorsionado las tendencias y dificultado los análisis sectoriales.

Todas estas razones no inhabilitan el desarrollo de esta nueva línea de investigación, en una etapa de mejoría del sector turístico, si bien suponen un importante inconveniente que puede ser resuelto con el diseño de metodologías que incluyan la realización de encuestas, entrevistas y trabajo de campo, lo cual implican un elevado coste económico y de tiempo.

A ello se unen otros condicionantes como son: 1 . desinterés por parte de los investigadores del turismo, centrados en otras temáticas novedosas como las Smart Cities, la turismofobia o la huella turística, entre otros, y 2. la falta de colaboración con profesionales de diferentes disciplinas y/o grupos de trabajo (geografía urbana, de los transportes, económica, del turismo...). De la literatura general, recogida en el apartado 3 del artículo, se desprende la importancia de la colaboración entre expertos. Esta se hace todavía más necesaria para abordar la relación turismo-AVE, puesto que permitiría el intercambio de perspectivas, metodologías y experiencias.

De esta manera se podrán abordar una serie de temáticas de gran interés, que pueden ser tratadas a diferentes escalas (regional, local e incluso de distrito y barrio) dando como resultado tesis doctorales y trabajos de fin de máster. Así, se darían respuesta a numerosas preguntas, como: ¿Qué papel que ha desempeñado el AVE en la creación, consolidación y promoción de destinos?; ¿Cuáles son sus repercusiones en función del tipo de ciudad (dependiendo de su ubicación y dimensiones)?; ¿Qué factores intervienen?; ¿Cuáles son las relaciones y competencia entre destinos?; ¿ Existe relación entre las tipologías de viajeros y sus motivaciones y el grado de repetición de la visita al destino?; ¿Cómo ha afectado la ubicación de las estaciones en los procesos de terciarización y turistización de sus entornos?; ¿Qué papel tiene RENFE como agente? y ¿El AVE supone una estrategia de marketing territorial real y eficaz?

\section{CONCLUSIONES}

En las últimas décadas la alta velocidad ferroviaria ha sido estudiada por investigadores de diferentes países y disciplinas, existiendo una estrecha relación entre la inauguración de las líneas de alta velocidad y la producción científica sobre esta temática. Así, a escala nacional la llegada del tren a las diferentes ciudades españolas ha sido, generalmente,

Revista de Estudios Andaluces, vol. 34, núm. 1 (2017) pp.321-349. e-ISSN: 2340-2776 http://dx.doi.org/10.12795/rea.2017.i34.11

\section{(c) (i) (9)}

SinObraDerivada 4.0 Internacional 
el impulso que ha motivado a sus investigadores, o del entorno próximo, a escribir sobre el nuevo ferrocarril.

Tras el análisis realizado se observa la coincidencia de las temáticas, siendo común a todas las ciencias la preocupación por: 1 . el impacto de las líneas de alta velocidad en la accesibilidad de las ciudades lo que permite su integración y establecer modelos territoriales descentralizados; 2 . la ubicación de las estaciones y las transformaciones urbanas derivadas de su presencia; 3 . la competencia entre la alta velocidad y otras modalidades de transporte y 4 . las repercusiones en la actividad turística. Así, los resultados ofrecidos son, en la mayor parte de los casos coincidentes, y complementarios entre sí. La mayor parte de las investigaciones se han centrado en las transformaciones económicas, urbanas y en la evolución histórica de este medio de transporte, poniendo de relieve la sobrevaloración de los efectos positivos de la infraestructura y cómo produce un efecto polarizador en el territorio.

Hay que destacar la colaboración existente entre profesionales de diferentes disciplinas o áreas de investigación dentro de la geografía. Se crea así un corpus teórico y metodológico muy completo, que dentro de la diversidad, muestra la complementariedad entre los trabajos y líneas de aquellos que son más críticos y los que, por el contrario destacan las bondades de la alta velocidad.

Sin embargo, en el estudio de la relación turismo-alta velocidad se observa un importante vacío en la literatura científica española a pesar de que muchas de las ciudades afectadas por el AVE son importantes destinos de turismo urbano y de negocios (Barcelona, Madrid, Sevilla y Zaragoza), de turismo cultural (Córdoba, Segovia) y de sol y playa (Alicante y Málaga). En este marco debemos señalar la escasez de fuentes de información estadística en relación con el AVE y el turismo, lo que supone un reto metodológico que debe ser solventado en investigaciones futuras para poder comprender el impacto que sobre este sector económico ha tenido el AVE y también establecer estrategias políticas.

\section{Agradecimientos}

Este artículo se enmarca en el Programa I+D "Los conjuntos patrimoniales como activos turísticos de la Comunidad de Madrid. Problemas y oportunidades en perspectiva territorial" (PTR-TUR-CM). Ref.S2015/HUM3317 (2016-2018), coordinador: Miguel Ángel Troitiño y en "Transformaciones del paisaje urbano histórico inducidas por el turismo: contradicciones y controversias, gobierno y gobernanza local (CSO2016-75470R), convocatoria 2016 de proyectos I+D+i, Programa Estatal de Investigación desarrollo e innovación orientada a los retos de la sociedad. IP: Manuel de la Calle y María Velasco.

Revista de Estudios Andaluces, vol. 34, núm. 1 (2017) pp. 321-349. e-ISSN: 2340-2776 http://dx.doi.org/10.12795/rea.2017.i34.11

\section{c) (i) $(9)$}




\section{REFERENCIAS}

Adler, N., Pels, E. y Nash, C. (2010). High-speed rail and air transport competition: Game engineering as tool for cost-benefit analysis. Transportation Research Part B: Methodological, 44(7), 812-833. https://doi.org/10.1016/j.trb.2010.01.001

Albalate del Sol, D., y Bel i Queralt, G. (2011). Cuando la economía no importa: auge y esplendor de la alta velocidad en España. Revista de Economía Aplicada, 19(55), 171190.

Alonso, P., y Bellet, C. (2009). El tren de alta velocidad y el proyecto urbano. Un nuevo ferrocarril para la Zaragoza del tercer milenio. Scripta Nova: revista electrónica de geografía y ciencias sociales, Vol. XIII, 281, 1-32.

Álvarez-San Jaime, O. y Herce, J. A. (1993). Nuevas líneas ferroviarias de alta velocidad en España y sus efectos económicos. Revista de Economía Aplicada, 1(1), 5- 32. https://doi.org/10.1016/j.tranpol.2016.04.006

Álvarez-San Jaime, Ó., Cantos-Sánchez, P., Moner-Colonques, R., y Sempere-Monerris, J. J. (2016). Rail access charges and internal competition in high speed trains. Transport Policy, 49, 184-195. https://doi.org/10.1016/j.tranpol.2016.04.006

Auphan, E. (2002). Le TGV Méditerranée: un pas décisif dans l'évolution du modèle français à grande vitesse. Méditerranée, 98(1), 19-26. https://doi.org/10.3406/medit.2002.3238

Bazin-Benoit, S., Beckerich, C., y Delaplace, M. (2010). Desserte ferroviaire à grande vitesse, activation des ressources spécifiques et développement du tourisme: le cas de l'agglomération rémoise. Belgeo. Revue belge de géographie, (1-2), 65-78. https://doi.org/10.4000/belgeo.6669

Bazin-Benoit, S., Beckerich, C., y Delaplace, M. (2013). Desserte TGV et villes petites et moyennes. Une illustration par le cas du tourisme à Arras, Auray, Charleville-Mézières et Saverne. Les Cahiers scientifiques du transport, 63, 33-61.

Bazin-Benoit, S., Beckerich, C. y Delaplace, M. (2014). Valorisation touristique du patrimoine et dessertes TGV dans les villes intermédiaires à moins d'1h30 de Paris: les cas de Reims, Metz, Le Mans et Tours. Revue d'économie régionale et urbaine, 5, 865883. https://doi.org/10.3917/reru.145.0865

Revista de Estudios Andaluces, vol. 34, núm. 1 (2017) pp.321-349. e-ISSN: 2340-2776 http://dx.doi.org/10.12795/rea.2017.i34.11

\section{(c) (i) (3)}

SinObraDerivada 4.0 Internacional 
Bazin-Benoit, S. y Delaplace, M. (2015). Mise en service des dessertes TGV et gouvernance dans le domaine du tourisme: le cas de villes françaises. Revue Géographique de l'Est, 55 (3-4), 1-18.

Bel, G. (2011). Infrastructure and nation building: The regulation and financing of network transportation infrastructures in Spain (1720-2010). Business History, 53(5), 688-705. https://doi.org/10.1080/00076791.2011.599591

Bellet, C. (2013). Transporte y desarrollo territorial. El estudio de los efectos asociados a la implantación de la alta velocidad ferroviaria a través del caso español. Transporte y Territorio, 8, 117-137.

Bellet, C, Alonso, P. y Gutiérrez, A. (2012).The High-Speed Rail in Spanish Cities: Urban Integration and Local Strategies for Socioeconomic Development. Territorial Implications of High-Speed Rail: A Spanish Perspective, Farnham, Ashgate Publishing, 163-196.

Bellet, C, Casellas, A. y Alonso, P. (2010). Infraestructuras de transporte y territorio: los efectos estructurantes de la llegada del tren de alta velocidad en España. Boletín de la Asociación de Geógrafos Españoles, 52, 143-163.

Bellet, C. y Gutiérrez, A. (2011). Ciudad y ferrocarril en la España del siglo XXI. La integración de alta velocidad ferroviaria en el medio urbano. Boletín de la Asociación de Geógrafos Españoles, 55, 251-279.

Bellet, C. y Llop, J. M. (2005). El proceso del proyecto urbanístico y territorial del TAV/AVE en Lleida. Ingeniería y territorio, 70, 82-87.

Bonnafous, A. (1987). The regional impact of the TGV. Transportation, 14(2), 127- 137. https://doi.org/10.1007/BF00837589

Boscá, J. E., Escribá, J. y Murgui, M. J. (2011). La efectividad de la inversión en infraestructuras públicas: una panorámica para la economía española y sus regiones. Investigaciones Regionales, 20, 195-217.

Burckhart, K., Martí-Henneberg, J. y Tapiador, F. (2008). Cambio de hábitos y transformaciones territoriales en los corredores de alta velocidad ferroviaria: Resultados de una encuesta de viajeros en la línea Madrid-Barcelona. Scripta Nova: revista electrónica de geografía y ciencias sociales, Vol. XII, 270 (46), 1-13.

Calvo Poyo, F. J. y de Oña López, J. (2005). Competitividad del ferrocarril de alta velocidad en el ámbito del transporte regional: el eje transversal andaluz. Ingeniería y territorio, 70, 72-79. 
Casellas, A, Bellet, C. y Alonso, P. (2011). Gobernanza, infraestructuras y desarrollo territorial: análisis a través de una estación de tren de alta velocidad. Ería: Revista cuatrimestral de geografía, 84, 159-172.

Charlton, C. y Gibb, R. (2000).International surface passsenger transport. En: B. Hoyle y R. Knowles (Eds.): Modern Transport Geography. 291-310. Londres: John Wiley and Sons.

Cinotti, É., y Treboul, J. B. (2000). Les TGV européens: Eurostar, Thalys. París: Presses universitaires de France, $126 \mathrm{p}$.

Coronado, J. M., Garmendia, M., Moyano, A., y Ureña, J. M. (2013). Assessing Spanish HSR network utility for same-day tourism. Recherche Transports Sécurité, 3, 161-175. https://doi.org/10.4074/S0761898013003026

Coronado, J. M. y Rivas, A. (2005). La movilidad de alta velocidad en estaciones situadas en ciudades de tamaño pequeño: el corredor Madrid-Ciudad Real-Puertollano. Ingeniería y territorio, 70, 52-57.

Coto, P., Inglada, V. y Rey, B. (2007). Effects of network economies in high-speed rail: the Spanish case. The Annals of Regional Science, 41(4), 911-925. https://doi.org/10.1007/s00168-007-0134-6

Delaplace, M. (2012). Pourquoi les «effets» TGV sont-ils différents selon les territoires? L'hétérogénéité au cœur du triptyque «Innovations, Territoires, Stratégies». Recherche Transports Sécurité, 28(3), 290-302. https://doi.org/10.1007/s13547-012-0041-9

Delaplace, M., Pagliara, F., Perrin, J., y Mermet, S. (2014). Can High Speed Rail foster the choice of destination for tourism purpose? Procedia-Social and Behavioral Sciences, 111, 166-175. https://doi.org/10.1016/j.sbspro.2014.01.049

Díez, R. (2012a). High-speed rail (HSR) vs. air transportation: trendy competition in the transport geography of Spain. Information Technology Research Journal, 2(1), 8-19.

Díez, R. (2012b). La incidencia del turismo en la evolución de la conectividad aérea española (1970-2008). Cuadernos de Turismo, (29), 137-159.

Díez, R., y Sánchez Escolano, L. M. (2012). Infraestructuras de transporte y metropolización desde una perspectiva geográfica. Revista de Estudios Andaluces, 29, 116. https://doi.org/10.12795/rea.2012.i29.01

Revista de Estudios Andaluces, vol. 34, núm. 1 (2017) pp.321-349. e-ISSN: 2340-2776 http://dx.doi.org/10.12795/rea.2017.i34.11

\section{(c) (i) () $(9)$}


Dobruszkes, F. (2011). High-speed rail and air transport competition in Western Europe: A supply-oriented perspective. Transport policy, 18(6), 870-879. https://doi.org/10.1016/j.tranpol.2011.06.002

Dobruszkes, F., Dehon, C., y Givoni, M. (2014). Does European high-speed rail affect the current level of air services? An EU-wide analysis. Transportation Research Part A: Policy and Practice, 69, 461-475. https://doi.org/10.1016/j.tra.2014.09.004

Esteban, V. (1998). La alta velocidad ferroviaria en la Unión Europea. Su impacto urbano en Francia y España. Geographicalia, 36, 19-32.

Facchinetti-Mannone, V. (2005). Efectos espaciales de las estaciones del TGV implantadas en la periferia de las ciudades pequeñas. Ingeniería y territorio, 70, 22-27.

Feliu, J. (2012). High-speed rail in European medium-sized cities: stakeholders and urban development. Journal of urban planning and development, 138(4), 293-302. https://doi.org/10.1061/(ASCE)UP.1943-5444.0000123

García, M. (2007). Entidades de planificación y gestión turística a escala local. El caso de las ciudades Patrimonio de la Humanidad de España. Cuadernos de Turismo, 20, 79-102.

Garmendia, M., Ureña, J. M., y Coronado, J. M. (2011). Cambios en la estructura territorial debidos a nuevas conexiones de alta velocidad en territorios aislados: la provincia de Ciudad Real en España. EURE (Santiago), 37(110), 89-115. https://doi.org/10.4067/S0250-71612011000100004

Garmendia, M., Ribalaygua, C., y Ureña, J. M. (2012). High-speed rail: implication for cities. Cities, 29, 26-31. https://doi.org/10.1016/j.cities.2012.06.005

Garmendia, M., Ureña, J. M., Ribalaygua, C., Leal, J., y Coronado, J. M. (2008). Urban residential development in isolated small cities that are partially integrated in metropolitan areas by high-speed train. European urban and regional studies, 15(3), 249-264. https://doi.org/10.1177/0969776408090415

Garmendia, M., Ureña, J. M., y Coronado, J. M. (2011). Long-distance trips in a sparsely populated region: The impact of high-speed infrastructures. Journal of Transport Geography, 19(4), 537-551. https://doi.org/10.1016/j.jtrangeo.2010.06.002

Gil, E. (2010). Caracterización del turismo e incidencia potencial y real de la implantación de la alta velocidad en Segovia. Lurralde: Investigación y espacio, 33, 119-145.

Guirao Abad, B., y Menéndez Martínez, J. M. (2005). Alta velocidad ferroviaria en el Plan Estratégico de Infraestructuras y Transporte (2005-2020). Ingeniería y territorio, 70, 3641.

Revista de Estudios Andaluces, vol. 34, núm. 1 (2017) pp. 321-349. e-ISSN: 2340-2776 http://dx.doi.org/10.12795/rea.2017.i34.11

(c) (i) (2) Es Esta obra se distribuye con la licencia Creative Commons Reconocimiento-NoComercialSinObraDerivada 4.0 Internacional 
Givoni, M. (2006). Development and impact of the modern high-speed train: a review. Transport Reviews, 26 (5), 593-611. https://doi.org/10.1080/01441640600589319

Givoni, M. (2007). Environmental benefits from mode substitution - comparison of the environmental impact from aircraft and high-speed train operation. International Journal of Sustainable Transport, 1 (4), 209-230. https://doi.org/10.1080/15568310601060044

González, M. P., Aguilera, M. J., Borderías, M. P. y Santos, J. M. (2005). Cambios en las ciudades de la línea de alta velocidad Madrid-Sevilla desde su implantación. Cuadernos geográficos, 36(1), 527-547.

González-Savignat, M. (2004a). Competition in air transport: the case of the high speed train. Journal of transport economics and policy, 38, 77-107. https://doi.org/10.1080/0144164032000083103

González-Savignat, M. (2004b). Will the high-speed train compete against the private vehicle?. Transport Reviews, 24(3), 293-316.

Gutiérrez, J. (2001).Location, economic potential and daily accessibility: an analysis of the accessibility impact of the high-speed line Madrid-Barcelona-French border. Journal of Transport Geography, 9(4), 229-242. https://doi.org/10.1016/S09666923(01)00017-5

Gutiérrez, J. (2004). El tren de alta velocidad y sus efectos espaciales/The high-speed train and its spatial effects. Investigaciones Regionales, 5, 199-221.

Gutiérrez, J. (2013). Transport Geography in Spain. Journal of Transport Geography, (28), 216-218. https://doi.org/10.1016/j.jtrangeo.2012.12.010

Gutiérrez, J., González, R., y Gómez, G. (1996). The European high-speed train network: predicted effects on accessibility patterns. Journal of Transport Geography, 4(4), 227238. https://doi.org/10.1016/S0966-6923(96)00033-6

Gutiérrez J.A., Naranjo J. M., Jaraíz F. J., y Ruiz, E. E. (2015). Estimación de la cohesión social en los municipios españoles tras la implantación de la Alta Velocidad ferroviaria. Boletín de la Asociación de Geógrafos Españoles, 69, 113-138.

López, A. (2005).La contribución de las nuevas infraestructuras ferroviarias a la mejora del transporte regional e interregional: el caso de Cataluña. Ingeniería y territorio, 70, 66-71.

Revista de Estudios Andaluces, vol. 34, núm. 1 (2017) pp.321-349. e-ISSN: 2340-2776 http://dx.doi.org/10.12795/rea.2017.i34.11

\section{(c) (i) (3)}

SinObraDerivada 4.0 Internacional 
Martí-Henneberg, J. (2013). European integration and national models for railway networks (1840-2010). Journal of Transport Geography, 26, 126-138. https://doi.org/10.1016/j.jtrangeo.2012.09.004

Martín, S. (2013). La red española de alta velocidad ferroviaria: análisis mediante un modelo gravitacional. Revista de Estudios Andaluces, 30, 78-101. https://doi.org/10.12795/rea.2013.i30.04

Martín, J. C., Gutiérrez, J., y Román, C. (2004). Data envelopment analysis (DEA) index to measure the accessibility impacts of new infrastructure investments: The case of the high-speed train corridor Madrid-Barcelona-French border. Regional Studies, 38(6), 697712. https://doi.org/10.1080/003434042000240987

Martín, J. C. y Nombela, G. (2008). Impacto de los nuevos trenes AVE sobre la movilidad. Revista de Economía Aplicada, 16(47), 5.

Masson, S., y Petiot, R. (2009). Can the high speed rail reinforce tourism attractiveness? The case of the high speed rail between Perpignan (France) and Barcelona (Spain). Technovation, 29(9), 611-617. https://doi.org/10.1016/j.technovation.2009.05.013

Menéndez, J.M., Coronado, J. y Rivas, A. (2002). El AVE en Ciudad Real y Puertollano: Notas sobre su incidencia en la movilidad y el territorio. Cuadernos de Ingeniería y territorio, 2, 79p. Universidad de Castilla-La Mancha.

Moyano, A., Coronado, J. M. y Garmendia, M. (2016). How to Choose the Most Efficient Transport Mode for Weekend Tourism Journeys: An HSR and Private Vehicle Comparison. The Open Transportation Journal, 10 (1), 84-96. https://doi.org/10.2174/1874447801610010084

Pagliara, F., Vassallo, J. y Román, C. (2012). High-speed rail versus air transportation: case study of Madrid-Barcelona, Spain. Transportation Research Record: Journal of the Transportation Research Board, (2289), 10-17. https://doi.org/10.3141/2289-02

Pueyo, A., Jover, J.A., y Zúñiga, M. (2012). Accessibility Evaluation of the Transportation Network in Spain during the First Decade of the Twenty-first Century" En: Ureña, J.M. (Ed.), Territorial Implications of High Speed Rail: A Spanish Perspective. Territorial Implications of High Speed Rail, 83-104, Ashgate.

Pulido, J. I. (coord.) (2007). Debate: La influencia de las compañías aéreas de bajo coste en el mercado turístico español. Revista de análisis turístico, 3, 103-119.

RENFE (2014). Balance Política Comercial 2013 y novedades 2014. Ministerio de Fomento. [En línea] Disponible en:

Revista de Estudios Andaluces, vol. 34, núm. 1 (2017) pp. 321-349. e-ISSN: 2340-2776 http://dx.doi.org/10.12795/rea.2017.i34.11 
https://www.fomento.gob.es/NR/rdonlyres/3DC66696-DBC6-410F-B74200DC52E7ADE4/123960/140320BalancePol\%C3\%ADticaComercialRenfe.pdf [última consulta 8 de febrero de 2016]

Rodríguez, M., Novales, M., y Arcay, A. (2005). Alta velocidad y territorio. Algunas experiencias internacionales. Ingeniería y territorio, 70, 4-11.

Ribalaygua, C. (2005). Estrategias de las pequeñas ciudades para acoger el AVE. Ingeniería y territorio, 70, 58-63.

Román, C., Espino, R. y Martín, J. C. (2007). Competition of high-speed train with air transport: The case of Madrid-Barcelona. Journal of Air Transport Management, 13(5), 277-284. https://doi.org/10.1016/j.jairtraman.2007.04.009

Román, C., Espino, R. y Martín, J. C. (2010). Analyzing competition between the high speed train and alternative modes. The case of the Madrid-Zaragoza-Barcelona Corridor. Journal of Choice Modelling, 3(1), 84-108. https://doi.org/10.1016/S17555345(13)70030-7

Rus, G. de e Inglada, V. (1993). Análisis coste-beneficio del tren de alta velocidad en España. Revista de Economía Aplicada, 1(3), 27-48.

Rus, G. de e Inglada, V. (1997). Cost-benefit analysis of the high-speed train in Spain. The Annals of Regional Science, 31(2), 175-188. https://doi.org/10.1007/s001680050044

Rus, G. de y Román, C. (2006). Análisis económico de la línea de alta velocidad MadridBarcelona. Revista de Economía Aplicada, 42, 35-79

Saladié, Ò, Clavé, S. A, Cortés-Jiménez, I., Young, A. F. y Young, R. (2014). La influencia de las rutas de vuelos de bajo coste en la elección del destino turístico. Cuadernos de Turismo, (34), 287-312.

Sánchez-Ollero, J. L., Pozo, A. G. y Mera, A. J. M. (2014). Una aproximación al impacto socioeconómico de la alta velocidad ferroviaria en Andalucía. Boletín de la Asociación de Geógrafos Españoles, 64, 341-356.

Santos, L., y de las Rivas Sanz, J. L. (2005). El proyecto urbanístico del AVE en Valladolid. Ingeniería y territorio, 70, 88-95.

Santos, J. M., Aguilera, M. J., Borderías, M. P. y González-Yanci, M. P. (2006). La movilidad interurbana en la línea de alta velocidad Madrid-Sevilla: rasgos definitorios a

Revista de Estudios Andaluces, vol. 34, núm. 1 (2017) pp.321-349. e-ISSN: 2340-2776 http://dx.doi.org/10.12795/rea.2017.i34.11

\section{(c) (i) (3)}

SinObraDerivada 4.0 Internacional 
los 10 años de su implantación. Anales de Geografía de la Universidad Complutense, 26, 147-165.

Serrano, J. M. (2000). El ferrocarril de Alta velocidad en España, evolución y perspectivas frente al tercer milenio. Nimbus: Revista de climatología, meteorología y paisaje, 5, 125154.

Serrano, J. M. (2004). Las redes de infraestructuras viarias de transportes terrestres entre la Península Ibérica y Francia; descoordinación e insuficiencias. Papeles de geografía, 39, 187-208.

Serrano, J. M., García, R., y Gil, S. (2010). La política de transporte ferroviario en España. Los corredores de alta velocidad: sus potenciales y limitaciones. Scripta Nova: revista electrónica de geografía y ciencias sociales, Vol. XIV, 331 (20).

Soria, H. (2010). Alta Velocidad y transformaciones urbanas en Valladolid. Ciudad, territorio y paisaje: Reflexiones para un debate multidisciplinar, 298-307.

Soulié, C. y Tricoire, J. (2002). Le grand livre du TGV. París: La Vie du rail, 351 p.

Spiekermann, K. y Wegener, M. (1994). The shrinking continent: new time-space maps of Europe. Environment and Planning B: Planning and Design, 21(6), 653-673. https://doi.org/10.1068/b210653

Spiekermann, K. y Wegener, M. (1996). Trans-European networks and unequal accessibility in Europe. European journal of regional development, 4(96), 35-42.

Tapiador, F. J., Burckhart, K. y Martí-Henneberg, J. (2009). Characterizing European high speed train stations using intermodal time and entropy metrics. Transportation Research Part A: Policy and Practice, 43(2), 197-208. https://doi.org/10.1016/j.tra.2008.10.001

Troin, J. F. (1995). Rail et aménagement du territoire: des héritages aux nouveaux défis. Saint-Remy-de-Provence: Edisud, 261 p.

Troin, J. F. (1997). Les gares T.G.V. et le territoire: débat et enjeux. Annales de géographie, Vol. 106, 593, 34-50.

Ureña, J. M. (2005). Alta Velocidad Ferroviaria (AVF) y nuevas actividades en tres situaciones territoriales. Ingeniería y territorio, 70, 42-49.

Ureña, J. M., Menerault, P., y Garmendia, M. (2009). The high-speed rail challenge for big intermediate cities: A national, regional and local perspective. Cities, 26(5), 266- 279. https://doi.org/10.1016/j.cities.2009.07.001

Revista de Estudios Andaluces, vol. 34, núm. 1 (2017) pp. 321-349. e-ISSN: 2340-2776 http://dx.doi.org/10.12795/rea.2017.i34.11 
Vera, J. F. e Ivars, J. A. (2009). Spread of low-cost carriers: tourism and regional policy effects in Spain. Regional Studies, 43(4), 559-570. https://doi.org/10.1080/00343400701874164

Revista de Estudios Andaluces, vol. 34, núm. 1 (2017) pp.321-349. e-ISSN: 2340-2776 http://dx.doi.org/10.12795/rea.2017.i34.11

\section{(c) (i) $(9)$} SinObraDerivada 4.0 Internacional 